\title{
Cigarette smoke inhalation patterns and bronchial reactivity
}

\author{
D R TAYLOR, W D REID, P D PARÉ, J A FLEETHAM \\ From the Department of Medicine, University of British Columbia, Vancouver, Canada
}

\begin{abstract}
The manner in which a cigarette is smoked varies considerably between individuals and may be an important determinant of the altered bronchial reactivity observed in cigarette smokers. Twenty smokers were examined to determine the relationship between cigarette smoke inhalation patterns and bronchial reactivity. Inhalation patterns were measured non-invasively with a respiratory inductive plethysmograph and these were related to the provocative concentration of histamine that caused a $20 \%$ fall in $\mathrm{FEV}_{1}\left(\mathrm{PC}_{20}\right)$ and to the cough threshold for inhaled citric acid. Histamine $\mathrm{PC}_{20}$ values were inversely correlated with depth and rate of inhalation. Cough threshold was inversely correlated with greater cigarette consumption and with depth of inhalation.
\end{abstract}

There is growing evidence that non-specific bronchial reactivity is greater in smokers than in non-smokers ${ }^{1-4}$ and that this effect is related to the numbers of cigarettes smoked. ${ }^{3}$ There are, however, several reports ${ }^{5-7}$ that have found no difference in bronchial reactivity between symptomless smokers and nonsmokers. Cigarette smoke inhalation patterns vary considerably between individuals, with large variations in the depth and rate of inhalation and the duration of breath hold. ${ }^{8}$ These factors are likely to modify airway deposition of cigarette smoke particulate material and as such may be important determinants of cigarette smoke related lung disease.

We have measured inhalation patterns and bronchial reactivity in a group of chronic smokers with normal pulmonary function to examine further the relationship between cigarette smoking and bronchial reactivity to inhaled histamine.

\section{Methods}

\section{SUBJECTS}

Twenty subjects (six men and 14 women) completed the study. Their ages ranged from 20 to 54 years and they smoked from 10 to 60 cigarettes a day, with a cumulative consumption ranging from four to 52 pack years. Eight subjects had a cough but none had any other symptoms suggesting atopy or asthma and none

Address for correspondence: $\operatorname{Dr} \mathbf{J}$ A Fleetham, Department of Medicine, UBC Health Sciences Centre Hospital, Vancouver, British Columbia V6T IW5, Canada. was taking any bronchodilator. All subjects had a forced expiratory volume in one second $\left(\mathrm{FEV}_{1}\right)$ and forced vital capacity (FVC) over $85 \%$ of the predicted value, on the basis of the best of three expirations into a spirometer (Collins Modular Function Analyser, Braintree, Massachusetts, USA). Subjects gave informed consent to the study, which was approved by the university ethics committee.

\section{PROTOCOL}

The study was carried out during the morning on two separate days. On day 1 monitoring of smoke inhalation patterns was performed and followed by an assessment of the airway response to inhaled histamine or the cough response to inhaled citric acid. On day 2 the other bronchial challenge test was performed. The order of administration for the two challenge tests was randomised. The bronchoconstrictor response to histamine has been shown to be unaffected by cigarette smoking immediately before the test. $^{10}$ On three additional consecutive days we restudied smoke inhalation patterns and cough threshold in five subjects to assess intrasubject variability.

\section{MONITORING OF SMOKE INHALATION PATTERNS}

Respiratory inductive plethysmography (Respitrace, Non-invasive Monitoring Systems Inc, Ardsley, New York) was used to monitor the pattern of breathing and smoke inhalation. "Calibration was carried out by the simultaneous equation method with subjects standing and semirecumbent. Validation against a known inspired volume from a Collins wet spirometer 
was performed with subjects semirecumbent before and after observation of inhalation pattern. A change of more than $10 \%$ in volume calibration occurred in three subjects and their results were excluded from the analysis.

After calibration each subject remained semirecumbent in a quiet room. Tidal breathing was monitored for 10 minutes, after which subjects were instructed to smoke two of their usual brand of cigarettes with an intervening rest period of 10 minutes. They were permitted to read during the period of observation and every effort was made to minimise any disturbance. Subjects were not informed of our specific interest in their breathing pattern. Each cigarette inhalation was noted by continuous observation through a one way mirror.

Signals from the respiratory inductive plethysmograph were recorded on a Grass 78 polygraph recorder. Mean values for tidal volume (VT), inspiratory time $(\mathrm{Ti})$, and mean inspiratory flow rate $(\mathrm{VT} / \mathrm{Ti})$ were calculated from 15 consecutive breaths during the final minute of tidal breathing in the initial rest period. During cigarette smoking, inhalation volume, $\left(\mathrm{VI}_{\mathrm{I}}\right.$, inhalation time $(\mathrm{TI})$, inhalation flow rate $(\mathrm{VI} / \mathrm{TI})$, and breath hold time were determined as mean values from all inhalations from both cigarettes apart from the first and last inhalation, which may be atypical. Inhalation volume $\left(V_{I}\right)$ is expressed as a ratio of the vital capacity $\left(\mathrm{V}_{\mathrm{I}} / \mathrm{VC}\right)$ and mean inhalation flow rate $\left(\mathrm{V}_{\mathrm{I}} / \mathrm{T}_{\mathrm{I}}\right)$ expressed as a ratio of the resting mean inspiratory flow rate $\left(\mathrm{VI}_{\mathrm{l}} / \mathrm{TI}: \mathrm{VT} / \mathrm{Ti}\right)$.

\section{AIR WAY RESPONSE TO HISTAMINE}

The airway response to inhaled histamine was determined by the technique of Juniper et $\mathbf{l}^{12}$ as modified by Lam et al. ${ }^{13}$ Doubling concentrations of histamine ranging from 0.03 to $16.0 \mathrm{mg} / \mathrm{ml}$ were administered until the maximum concentration had been given or a decrease in $\mathrm{FEV}_{1}$ of $20 \%$ or more had occurred. Each histamine solution was given for two minutes with a Bennett Twin nebuliser (output $0.23 \mathrm{ml} \mathrm{min}^{-1}$ ) at a flow rate of $81 \mathrm{~min}^{-1}$. Subjects breathed normally wearing a face mask and nose clip. Forced expiratory manoeuvres were performed 30 and 90 seconds and three minutes after inhalation of a control solution of phosphate buffered saline, and at similar intervals after each concentration of histamine.

The concentration of histamine producing a $20 \%$ decrease in $\mathrm{FEV}_{1}\left(\mathrm{PC}_{20}\right)$ from the control value was determined by interpolation. In the seven subjects who did not show a $20 \%$ decrease in $\mathrm{FEV}_{1}$ after the maximum dose of histamine the $\mathrm{PC}_{20}$ was obtained from the line of best fit on the log dose-response curve extrapolated to infinity.

COUGH THRESHOLD

The cough threshold was determined by using a modification of the technique described by Bickerman $\Rightarrow$ and Barach $^{14}$ and Empey et al. ${ }^{15}$ In a random single $\stackrel{5}{+}$ blind fashion each subject inhaled a control solution of $\bar{C}$ normal saline followed by progressively increasing concentrations (the percentages being $0 \cdot 5,1,2,4,6,8$, क्? $12,16,24,32,48$ and 64 ) of crystalline citric acid $\stackrel{\varnothing}{\varnothing}$ monohydrate (Fisher Scientific, New Jersey) dissolved in normal saline. Solutions were inhaled every five $\vec{\circ}$ minutes from a Bird micronebuliser, the subject carrying out a slow inspiratory vital capacity man- $\vec{\omega}$ oeuvre over five seconds. The cough threshold was $\circ$ defined as the lowest concentration of citric acid that $\vec{x}$ consistently elicited an involuntary cough during three $\frac{\gtrless}{\omega}$ separate inhalations.

STATISTICAL ANALYSIS

The relationship between variables was analysed by Spearman's rank correlation method in view of the $\bar{c}$ non-parametric distribution of the data.

\section{Results}

Smoking history, pulmonary function, cigarette smoke inhalation pattern, and histamine $\mathrm{PC}_{20}$ values $\frac{}{\circ}$ are presented for each individual in the table. There was considerable intersubject variability in the mean $\stackrel{\square}{\Omega}$ depth of inhalation $\mathrm{VI}_{\mathrm{I}} / \mathrm{VC}$ (range 7.6-34.5\%), mean $\Rightarrow$ rate of inhalation $\mathrm{V}_{\mathrm{I}} / \mathrm{T}_{\mathrm{I}} / \mathrm{VT}_{\mathrm{T}} / \mathrm{Ti}$ (range $0.65-3 \cdot 3$ ), and $\frac{3}{3}$ mean duration of breath hold (range 0-4.3 s). There $\vec{T}$ was no significant relationship between these three indices. There was also no significant relationship between cigarette smoke inhalation patterns and rest-으 ing breathing patterns. In our subgroup of five subjects the mean (SD) coefficients of variation $(\mathrm{SD} / \overline{\mathrm{x}} \times 100) \overline{-}$ for these indices were $3.6(1.8)$ for $\mathrm{VI} / \mathrm{VC}, 8 \cdot 2(3.2)$ for 3 . $\mathrm{VI}_{\mathrm{I}} / \mathrm{TI} / \mathrm{VT} / \mathrm{Ti}$, and 52 (17) for breath hold time.

Histamine $\mathrm{PC}_{20}$ values ranged from $2 \cdot 2$ to $>16 \mathrm{mg}$ / $\mathrm{ml}$. A cough threshold was obtained in all subjects, 응 ranging from $2 \%$ to $64 \%$ citric acid. In our subgroup of five subjects the mean (SD) coefficient of variation for cough threshold was $12 \cdot 6(4 \cdot 3)$.

Cough threshold values correlated positively with histamine $\mathrm{PC}_{20}$ values $(\operatorname{rho}(\rho)-0.38, \mathrm{p}<0.05)$ and $N$ correlated negatively with cigarette consumption N expressed as cigarettes/day $(\rho-0.39, \mathrm{p}<0.05)$ or 0 pack/years $(\rho-0.49, \mathrm{p}<0.05)($ fig 1$)$. There was no significant correlation between $\mathbf{P C}_{20}$ and cigarette consumption. When related to smoke inhalation patterns $\mathrm{PC}_{20}$ correlated negatively with depth of inhalation $\left(\mathrm{V}_{\mathrm{I}} / \mathrm{VC}\right)(\rho-0.38, \mathrm{p}<0.05)$ (fig 2) ando rate of inhalation $\mathrm{VI} / \mathrm{TI} / \mathrm{VT} / \mathrm{Ti}(\rho-0.42, \mathrm{p}<0.05) \stackrel{\mathrm{\Phi}}{\stackrel{\mathrm{d}}{ }}$ and cough threshold was also correlated negatively with depth of inhalation (VI/VC) $\left(\rho-0.50, \mathrm{p}<\frac{\varrho}{0}\right.$ 0.05 ) (fig 3). 
Smoking history, pulmonary function, smoke inhalation pattern, and bronchial reactivity to histamine in 20 normal subjects

\begin{tabular}{|c|c|c|c|c|c|c|c|c|c|c|c|c|c|}
\hline $\begin{array}{l}\text { Subject } \\
\text { No }\end{array}$ & Sex & $\begin{array}{l}\text { Age } \\
(y)\end{array}$ & $\begin{array}{l}\text { Cigar- } \\
\text { ettes/ } \\
\text { day }\end{array}$ & $\begin{array}{l}\text { Packs/ } \\
\text { year }\end{array}$ & $\begin{array}{l}F E V_{1} \\
(\% \\
\text { pred) }\end{array}$ & Cough & $V_{l}(l)$ & $\begin{array}{l}V I / V C \\
(\%)\end{array}$ & $\begin{array}{l}V_{I} / T_{l} \\
\left(l s^{-1}\right)\end{array}$ & $\begin{array}{l}V_{I} / T I / \\
V T / T i) \\
(\%)\end{array}$ & $\begin{array}{l}\text { Breath } \\
\text { hold } \\
\text { (mean, s) }\end{array}$ & $\begin{array}{l}P C_{20} \\
(\mathrm{mg} / \mathrm{ml})\end{array}$ & $\begin{array}{l}\text { Cough } \\
\text { threshold } \\
\text { (\% citric } \\
\text { acid) }\end{array}$ \\
\hline $\begin{array}{r}1 \\
2 \\
3 \\
4 \\
5 \\
6 \\
7 \\
8 \\
9 \\
10 \\
11 \\
12 \\
13 \\
14 \\
15 \\
16 \\
17 \\
18 \\
19 \\
20\end{array}$ & $\begin{array}{l}\mathbf{F} \\
\mathbf{F} \\
\mathbf{F} \\
\mathbf{M} \\
\mathbf{M} \\
\mathbf{F} \\
\mathbf{F} \\
\mathbf{F} \\
\mathbf{F} \\
\mathbf{F} \\
\mathbf{M} \\
\mathbf{F} \\
\mathbf{F} \\
\mathbf{F} \\
\mathbf{M} \\
\mathbf{F} \\
\mathbf{M} \\
\mathbf{M} \\
\mathbf{F} \\
\mathbf{F}\end{array}$ & $\begin{array}{l}39 \\
54 \\
28 \\
25 \\
41 \\
24 \\
28 \\
20 \\
29 \\
33 \\
29 \\
26 \\
38 \\
23 \\
29 \\
42 \\
22 \\
24 \\
22 \\
37\end{array}$ & $\begin{array}{l}15 \\
20 \\
10 \\
15 \\
40 \\
10 \\
25 \\
23 \\
25 \\
60 \\
25 \\
20 \\
30 \\
40 \\
30 \\
15 \\
20 \\
30 \\
20 \\
25\end{array}$ & $\begin{array}{r}13 \\
37 \\
4 \\
6 \\
46 \\
4 \\
17 \\
2 \\
15 \\
52 \\
19 \\
8 \\
15 \\
6 \\
20 \\
25 \\
4 \\
7 \\
5 \\
15\end{array}$ & $\begin{array}{r}118 \\
101 \\
97 \\
104 \\
91 \\
85 \\
105 \\
116 \\
94 \\
93 \\
91 \\
95 \\
97 \\
98 \\
95 \\
96 \\
101 \\
100 \\
98 \\
96\end{array}$ & $\begin{array}{l}- \\
- \\
- \\
\overline{+} \\
\pm \\
+ \\
- \\
- \\
- \\
- \\
- \\
+ \\
+ \\
+ \\
+ \\
+ \\
- \\
- \\
+\end{array}$ & $\begin{array}{l}0.334 \\
0.632 \\
0.553 \\
0.730 \\
1.160 \\
0.469 \\
0.660 \\
0.598 \\
0.508 \\
0.546 \\
1.132 \\
0.563 \\
1.354 \\
0.705 \\
0.703 \\
0.678 \\
1.475 \\
0.965 \\
0.504 \\
0.738\end{array}$ & $\begin{array}{r}7.6 \\
16.8 \\
12.9 \\
13.0 \\
24.0 \\
14.3 \\
16.0 \\
13.1 \\
14.8 \\
17.5 \\
21.2 \\
15.6 \\
34.5 \\
17.0 \\
14.0 \\
16.1 \\
25.1 \\
16.3 \\
11.9 \\
21.5\end{array}$ & $\begin{array}{l}0.386 \\
0.308 \\
0.382 \\
0.410 \\
0.226 \\
0.272 \\
0.710 \\
0.320 \\
0.461 \\
0.240 \\
0.434 \\
0.390 \\
0.534 \\
0.969 \\
0.512 \\
0.309 \\
1.267 \\
0.727 \\
0.485 \\
0.786\end{array}$ & $\begin{array}{r}84 \\
82 \\
182 \\
193 \\
123 \\
185 \\
65 \\
118 \\
137 \\
210 \\
196 \\
124 \\
108 \\
330 \\
133 \\
115 \\
239 \\
210 \\
152 \\
206\end{array}$ & $\begin{array}{l}0.6 \\
1.5 \\
0.9 \\
0.2 \\
1.5 \\
0.0 \\
0.7 \\
2.1 \\
0.4 \\
0.1 \\
3.1 \\
0.7 \\
0.4 \\
2.0 \\
4.3 \\
0.7 \\
1.1 \\
3.5 \\
2.2 \\
0.5\end{array}$ & $\begin{array}{c}64.0^{*} \\
64.0^{*} \\
16.5 \\
15.9 \\
7.8 \\
3.5 \\
70.0^{*} \\
99.9^{*} \\
10.3 \\
3.0 \\
11.0 \\
2.2 \\
6.0 \\
60.0^{*} \\
6.8 \\
22.0^{*} \\
3.5 \\
17.0^{*} \\
15.4 \\
4.4\end{array}$ & $\begin{array}{r}24 \\
12 \\
4 \\
16 \\
4 \\
16 \\
24 \\
64 \\
12 \\
2 \\
6 \\
12 \\
4 \\
12 \\
8 \\
16 \\
12 \\
24 \\
64 \\
16\end{array}$ \\
\hline $\begin{array}{l}\text { Mean } \\
\text { SEM }\end{array}$ & & $\begin{array}{r}30.7 \\
1.9\end{array}$ & $\begin{array}{r}24.9 \\
2 \cdot 6\end{array}$ & $\begin{array}{r}16 \cdot 0 \\
3 \cdot 2\end{array}$ & $\begin{array}{r}98 \cdot 6 \\
1.7\end{array}$ & $\begin{array}{r}8+ \\
12-\end{array}$ & $\begin{array}{l}0.750 \\
0.069\end{array}$ & $\begin{array}{r}17 \cdot 2 \\
1.3\end{array}$ & $\begin{array}{l}0.506 \\
0.059\end{array}$ & $\begin{array}{r}160 \\
14\end{array}$ & $\begin{array}{l}1 \cdot 3 \\
0 \cdot 0 \\
4 \cdot 1 \ddagger\end{array}$ & $\begin{array}{r}13 \cdot 4 \\
43 \cdot 2 \dagger \\
5 \cdot 0 \ddagger\end{array}$ & $\begin{array}{l}12 \cdot 1 \\
29 \cdot 1+\end{array}$ \\
\hline
\end{tabular}

${ }^{*}$ Derived by extrapolation.

†Geometric mean + SEM

tGeometric mean - SEM

$\mathrm{V}_{\mathrm{I}}-$ inhalation volume; $\mathrm{VC}$ - vital capacity; $\mathrm{VI}_{\mathrm{I}} / \mathrm{TI}-$ inhalation flow rate; $\mathrm{VT} / \mathrm{Ti}$-inspiratory flow rate; $\mathrm{PC}_{20}$-provocative concentration of histamine causing a $20 \%$ fall in $\mathrm{FEV}_{1} ;+$ indicates presence and - absence of cough.

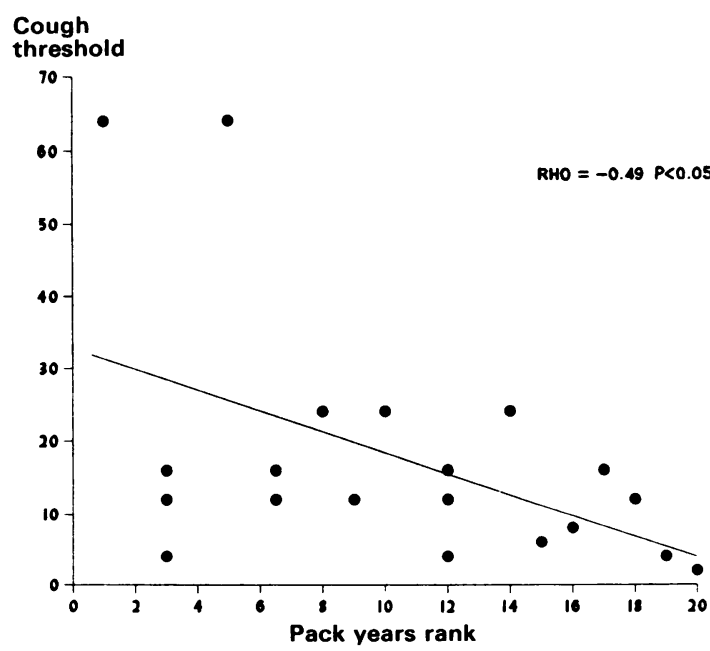

Fig 1 Cough threshold (\% citric acid) compared with ranked cigarette consumption (pack years) in 20 subjects.

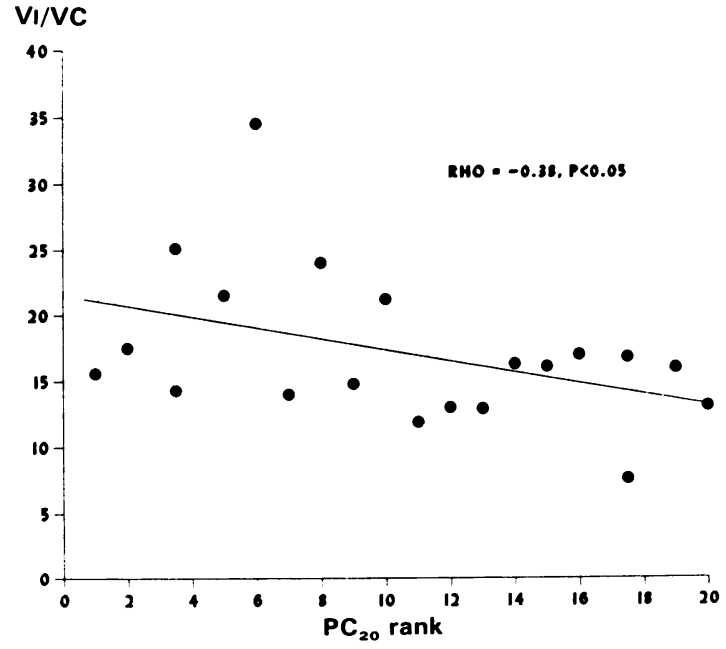

Fig 2 Ratio of cigarette smoke inhalation volume to vital capacity $\left(V_{I} / V C\right.$ ) compared with the ranked values for the concentration of histamine producing a $20 \%$ decrease in $F E V_{1}\left(P C_{20}\right)$ in 20 subjects. 


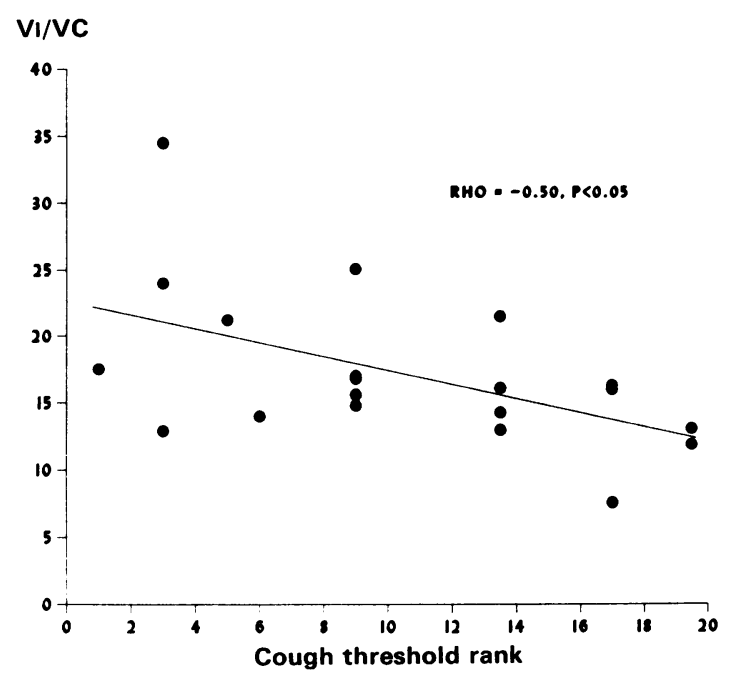

Fig 3 Ratio of cigarette smoke inhalation volume to vital capacity $(V I / V C)$ compared with the ranked values for cough threshold.

\section{Discussion}

The association between cigarette smoking and chronic airflow obstruction is well established. ${ }^{16}$ Nevertheless, many people smoke for prolonged periods without developing any airflow obstruction. It has been customary in epidemiological studies of cigarette smoking to quantify smoking history with a single variable, the total number of cigarettes smoked. This variable, however, does not take into account other important factors that may determine the relative concentration of smoke constituents reaching the lung, such as the degree of inhalation. There are some data on the frequency and possible significance of inhalation of cigarette smoke. Sixty per cent of moderate smokers have been found to inhale, ${ }^{17}$ and they develop more airflow obstruction ${ }^{18}$ than smokers who do not inhale. There is also evidence that smokers who inhale have significantly higher carboxyhaemoglobin and plasma nicotine concentrations. ${ }^{19}$ These data, however, have been obtained by subjective assessment of the degree of inhalation, which is notoriously unreliable. ${ }^{8}$

An objective study of smoking patterns has been difficult because most measuring devices have required some form of mouthpiece, which in itself may affect both the ability to smoke and the pattern of smoking. The respiratory inductive plethysmograph enables accurate monitoring of respiration without an airway and this has been used to quantify smoking patterns. ${ }^{812}$ In this study we have confirmed that in a group of smokers with no airflow obstruction there are large differences between subjects in inhalation rate and $\overrightarrow{\stackrel{F}{\rho}}$ volume and in duration of breath hold after inhala- $-\overrightarrow{0}$ tion. These different inhalation patterns might $\frac{}{0}$ influence the concentration and deposition of cigarette $\frac{\bar{\sigma}}{\bar{s}}$ smoke constituents within the lung. Aerosol deposi- $\bar{\varnothing}$ tion tends to increase with depth of inhalation, $\stackrel{\Omega}{\Omega}$ whereas more rapid inhalation may reduce lung $\infty$ deposition owing to proximal impaction. ${ }^{920}$ Further- $\vec{O}$ more, a breath hold after inhalation of cigarette smoke $\vec{\overrightarrow{ }}$ would favour gravity settlement of a small proportion $\vec{\omega}$ of particles that would otherwise remain airborne. ${ }^{20}$ Although some of the data are conflicting, there is $\vec{x}$ increasing evidence that chronic smoking is associated $\stackrel{\vec{\omega}}{.}$ with bronchial hyperreactivity. Gerrard and co- $\vec{\sigma}$ workers ${ }^{1}$ have reported greater bronchial reactivity in $\sigma$ smokers with symptoms than in age matched non- 음 smokers, and Malo et a $l^{2}$ have reported similar results $\overrightarrow{-}$ in symptomless smokers. Buczko and colleagues ${ }^{3}$ also found greater non-specific airway responsiveness in smokers than in non-smokers and showed a relationship to the amount smoked. In a large prospective $\vec{A}$ study Taylor and coworkers ${ }^{4}$ showed that, in men with $\mathscr{\infty}_{\circ}$ a baseline $\mathrm{FEV}$, over $80 \%$ predicted, bronchial reactivity was significantly greater among smokers and slightly greater among ex-smokers than among nonsmokers, and that the increased bronchial reactivity in $\bar{\partial}$ the smokers was associated with an accelerated decline of $\mathrm{FEV}_{1}$. Several studies ${ }^{5-7}$ have found no difference in $\stackrel{\varnothing}{\varnothing}$ histamine response between smokers and non-smok- $\overrightarrow{\overrightarrow{0}}$ ers. These investigations, however, examined young 3 symptomless smokers and as such may have selected $\supset$ the less responsive subjects. Our results are consistent? with the evidence that chronic cigarette smoking is associated with increased bronchial reactivity and 0 show that cigarette smoke inhalation patterns are $\tilde{x}$ significant determinants of this increased bronchial reactivity. Both the bronchoconstrictor response to histamine and the cough response were enhanced in 0 the subjects who inhaled most deeply. Furthermore, subjects who inhaled faster also had increased bron-응 choconstrictor responses. Our results do not support $\rightarrow$ an alternative hypothesis-namely, that increased bronchial reactivity in smokers might cause them to modify their inhalation pattern in an attempt to minimise the irritant effects of the cigarette smoke. N

Wanner and co-workers ${ }^{21}$ have recently demon- N strated that the variability in airway responsiveness to응 histamine in normal smokers is related to differences inco the dose deposited in the airways. As the dose of $\frac{}{\mathbb{D}}$ histamine deposited is related in part to breathing? pattern, an alternative explanation for the relationship 0 between cigarette smoke inhalation patterns and increased bronchial reactivity is that subjects who inhale cigarette smoke most deeply also inhale larger $\stackrel{\mathbb{Q}}{\stackrel{Q}{\perp}}$ quantities of the provocative agent. This explanation is not valid for the cough threshold data, as this was 
performed with a slow vital capacity manoeuvre. The histamine bronchial challenge was performed over two minutes of tidal breathing and we do not have measurements of tidal volume at this time. We do know that before measurement of smoke inhalation patterns there was no significant relationship between smoke inhalation pattern and resting breathing pattern. We think therefore that the relationship between smoke inhalation patterns and bronchial reactivity is unlikely to be due to a greater depth of inhalation with histamine in subjects with large inhaled volumes during cigarette smoking.

Cough is a frequent manifestation of bronchial hyperreactivity, yet there are few published reports on the variability of cough threshold in health and disease. As such, measurement of cough threshold represents a valuable additional method of assessing non-specific bronchial reactivity. This study confirms the large intersubject differences in cough threshold observed in previous reports ${ }^{141522}$ and shows that cough threshold is related to cigarette consumption and depth of inhalation. The greater the cigarette consumption and the deeper the smoke inhalation, the lower the cough threshold. Cough and wheeze are major symptoms of increased bronchial reactivity; yet some patients with asthma present primarily with cough, whereas others have bronchoconstriction and no cough. ${ }^{23}$ The present study shows that cough threshold is related to bronchial reactivity to histamine in chronic smokers. Previous reports suggest that cough and bronchoconstriction are due to quite different mechanisms. Inhaled bupivacaine blocks cough induced by citric acid but not bronchoconstriction induced by histamine in non-asthmatic subjects, ${ }^{24}$ and inhaled lignocaine blocks cough but not the bronchoconstrictor response to inhaled distilled water in subjects with asthma. ${ }^{25}$ It has also been shown that absence of a permeant anion in iso-osmolar aerosols causes cough but not bronchoconstriction. ${ }^{26}$

This study was supported by the British Columbia Lung Association. DRT was a Canadian Lung Association fellow, WDR a Canadian Lung Association physiotherapy fellow, and JAF a British Columbia Health Care Research Foundation scholar.

\section{References}

1 Gerrard JW, Cockcroft DW, Mink JT, Cotton DJ, Poonawala R, Dosman J. Increased non-specific bronchial reactivity in cigarette smokers with normal lung function. Am Rev Respir Dis 1980;122:577-81.

2 Malo JL, Filiatrault S, Martin RR. Bronchial responsiveness to inhaled methacholine in young asymptomatic smokers. J Appl Physiol 1982;52:1464-70.
3 Buczko GB, Day A, Vanderdoelen JL, Boucher R, Zamel N. Effects of cigarette smoking and short-term smoking cessation on airway responsiveness to inhaled methacholine. Am Rev Respir Dis 1984;129:12-4.

4 Taylor RG, Joyce H, Gross E, Holland F, Pride NB. Bronchial reactivity to inhaled histamine and annual rate of decline in $\mathrm{FEV}_{1}$ in male smokers and exsmokers. Thorax 1985;40:9-16.

5 Brown NE, McFadden ER, Ingram RH. Airway response to inhaled histamine in asymptomatic smokers and non-smokers. J Appl Physiol 1977;42:508-13.

6 Taylor RG, Clarke SW. Bronchial reactivity to histamine in young male smokers with normal lung function. Thorax 1984;39:236-7.

7 Kennedy SM, Elwood RK, Wiggs BJR, Paré PD, Hogg JC. Increased airway mucosal permeability of smokers: relationship to airway reactivity. $\mathrm{Am} \operatorname{Rev}$ Respir Dis 1984;129:143-8.

8 Tobin MJ, Jenouri G, Sackner MA. Subjective and objective measurement of cigarette smoke inhalation. Chest 1982;82:696-700.

9 Brain JD, Valberg PA. Deposition of aerosol in the respiratory tract. Am Rev Respir Dis 1979;120:1325-72.

10 McIntyre EL, Ruffin RE, Alpers JH. Lack of short-term effects of cigarette smoking on bronchial sensitivity to histamine and methacholine. Eur J Respir Dis 1982;63: 535-42.

11 Tobin MJ, Sackner MA. Monitoring smoking patterns of low and high tar cigarettes with inductive plethysmography. Am Rev Respir Dis 1982;126:258-64.

12 Juniper EF, Frith PA, Dunnett C, Cockcroft DW, Hargreave FE. Reproducibility and comparison of responses to inhaled histamine and methacholine. Thorax 1978;33:705-10.

13 Lam S, Wong R, Chan-Yeung M. Nonspecific bronchial reactivity in occupational asthma. $J$ Allergy Clin Immunol 1979;63:28-34.

14 Bickerman JA, Barach AL. The experimental production of cough in human subjects induced by citric acid aerosols. Preliminary studies on evaluation of antitussive agents. Am J Med Sci 1954;228:156-63.

15 Empey DW, Laitinen LA, Jacobs L, Gold WM, Nadel JA. Mechanisms of bronchial hyperreactivity in normal subjects after upper respiratory tract infection. Am Rev Respir Dis 1976;113:131-9.

16 Fletcher C, Peto R, Tinker C, Speizer FE. The natural history of chronic bronchitis and emphysema. Oxford: Oxford University Press, 1976.

17 Warner KE, Gori GB, Lynch CJ. Towards less hazardous cigarettes. JAMA 1979;241:2143-4.

18 White JR, Froeb HF. Small-airways dysfunction in nonsmokers chronically exposed to tobacco smoke. $N$ Engl J Med 1980;302:720-3.

19 Turner JAM, Sillett RW, McNicol MW. Effect of cigar smoking on carboxyhaemoglobin and plasma nicotine concentration in primary pipe and cigar smokers and ex-cigarette smokers. Br Med J 1977; ii:1387-9.

20 Pavia D, Thomson MI, Clarke SW, Shannon HS. Effect of lung function and mode of inhalation on penetration of aerosol in the human lung. Thorax 1977;32:194-7.

21 Wanner A, Brodnan JM, Perez J, Henke KG, Kim CS. Variability of airway responsiveness to histamine 
aerosol in normal subjects. Role of desposition. Am Rev Respir Dis 1985;131:3-7.

22 Pounsford JC, Saunders KB. Diurnal variation and adaptation of the cough response to citric acid in normal subjects. Thorax 1985;40:657-61.

23 McFadden ER. Exertional dyspnoea and cough as preludes to acute attacks of bronchial asthma. $N$ Engl J Med 1975;292:555-9.

24 Thomson $\mathrm{N}$. The effect of different pharmacological agents on respiratory reflexes in normal and asthmatic subjects. Clin Sci 1979;56:235-41.

25 Sheppard D, Rizk N, Boushey HA, Bethel RA. Mechanism of cough and bronchoconstriction induced by distilled water aerosol. Am Rev Respir Dis 1983;127: 691-4.

26 Eschenbacher WL, Boushey HA, Sheppard D. Alteration in osmolarity of inhaled aerosols cause bronchoconstriction and cough, but absence of a permeant anion causes cough alone. Am Rev Respir Dis 1984;129: 211-5. 